\title{
Choline-based biodegradable ionic liquid catalyst for Mannich-type reaction
}

\author{
PENG HUAN ${ }^{\mathrm{a}}$, HU YULIN ${ }^{\mathrm{b}}, \mathrm{XING}_{\mathrm{RONG}}^{\mathrm{a}, \mathrm{b}}$ and FANG DONG ${ }^{\mathrm{a}, \mathrm{b}, *}$ \\ ${ }^{a}$ College of Chemical Engineering, Nanjing Tech University, Nanjing 210009, People's Republic of China \\ ${ }^{\mathrm{b}}$ School of Chemistry \& Environmental Engineering, Yancheng Teachers University, Yancheng 224002, \\ People's Republic of China \\ e-mail: fangdong106@sina.com
}

MS received 2 February 2016; revised 20 October 2016; accepted 21 October 2016

\begin{abstract}
A three-component Mannich-type reaction of aromatic aldehydes, ketones, and amines was catalyzed by a novel choline-based acidic ionic liquid. The proposed catalyst was a Lewis-Brønsted dual acid catalyst as well as water-tolerant. The $\beta$-amino carbonyl compounds were obtained at room temperature in reasonable to good yields ranging from 63 to $98 \%$. After the reaction, the catalyst could be recycled and reused for 5 times without obvious decrease of the yield. Further, the catalyst was environment-friendly with a significant biodegradation rate.
\end{abstract}

Keywords. Mannich-type reaction; choline; Lewis-Brønsted acid; catalysis; biodegradation.

\section{Introduction}

The Mannich-type reaction is a basic C-C bond forming multi-component reaction (MCR) which involves an amino alkylation of an acidic proton beside a carbonyl functional group by formaldehyde and a primary or secondary amine or ammonia. ${ }^{1}$ The products of Mannich reaction, $\beta$-amino carbonyl compound, are synthetic intermediates of huge value. It is widely employed in the organic synthesis of natural compounds, medicine and biologically active compounds. ${ }^{2}$ Today, it has shown broad applicability in other areas such as pesticides, explosives, dyes and paints. Most Mannich reactions are catalyzed by Lewis acid or Brønsted acid. ${ }^{3}$ In recent years, the researchers continued to study new synthetic methods and new catalysts including $\mathrm{TMG}^{4}{ }^{4} \mathrm{Sm}(\mathrm{OTf})_{3},{ }^{5} \mathrm{Fe}\left(\mathrm{HSO}_{4}\right)_{3} / \mathrm{SiO}_{2},{ }^{6}$ triphenylphosphine, ${ }^{7}$ nano- $\mathrm{Mn}\left(\mathrm{HSO}_{4}\right)_{2},{ }^{8}$ Zeolite $^{9}$ were reported.

Choline-based ionic liquids are widely applied in many areas such as the sustainable chemistry, ${ }^{10}$ synthetic chemistry ${ }^{11}$ and catalysis, ${ }^{12}$ due to the excellent physical, chemical properties, environmental friendliness and low prices. Abbott et al., proposed a novel deep eutectic ionic liquid based on choline chloride, and it showed a significant function in catalysis. ${ }^{13}$ On the basis of the research of choline-based ionic liquids,

\footnotetext{
*For correspondence
}

Satasia et al., designed a new sulfate-functionalized cholinium cation and catalyzed formamide synthesis by grindstone chemistry. ${ }^{14}$ Apart from Brønsted acid ${ }^{15}$ or Lewis-Brønsted acid, choline-based ionic liquids ${ }^{16}$ were also designed and synthesized. It has been proved that all of them have significant catalytic activity and are friendlier for the environment than conventional ionic liquids which have catalyzed many reactions like Biginelli reaction, ${ }^{15}$ Mannich reaction, ${ }^{16}$ KabachnikFields reaction, ${ }^{17}$ etc.

In continuation of our work on MCRs, ${ }^{18}$ and considering the importance of combined catalytic systems, the choline-based functional Lewis-Brønsted dual acid ionic liquid catalyst (Figure 1) was discovered and used as the catalyst in the Mannich-type reaction under mild reaction conditions. Its use as a novel catalyst for the synthesis of $\beta$-amino carbonyl compound via Mannich-type reaction has also been explored.

\section{Experimental}

\subsection{Materials and methods}

All the reagents and chemicals (AR grade) were procured from Sinopharm Chemical Reagent Co. Ltd. and used as received. The sludge used in the biodegradation rate test was supplied by Nanjing Sewage Treatment Plant, China.

The Elemental analyses were done using a PerkinElmer CHN analyzer. The IR spectra ( $\mathrm{KBr}$ pellet) were 


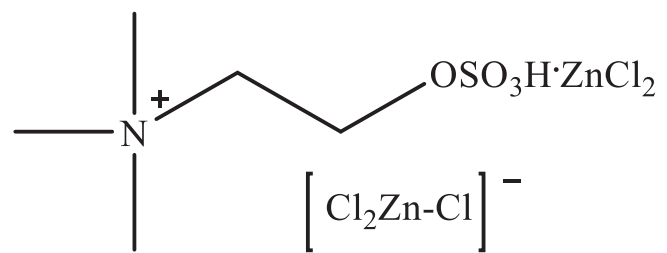

Figure 1. Structure of Lewis-Brønsted choline-based ionic liquid.

recorded on a Bruker WERTEX80 spectrometer and expressed in $\mathrm{cm}^{-1}$. ${ }^{1} \mathrm{H}$ NMR spectra were recorded on a Bruker DRX300 (300 MHz) and Bruker Ultrashield (400 MHz) spectrometer. ${ }^{13} \mathrm{C}$ NMR spectra were recorded on a Bruker DRX300 (75 MHz) and Bruker Ultrashield (101 MHz) spectrometer. Mass spectra were obtained with an automated Fininigan TSQ Quantum Ultra AM (Thermal) LC/MS spectrometer. Thermal stability measurements were conducted using a NETZSCH STA 449F5 system.

\subsection{Synthesis of Lewis-Brønsted choline-based Ionic liquid ([Ch-OSO$\left.\left.{ }_{3} \mathrm{H}\right] \mathrm{Cl} \cdot 2 \mathrm{ZnCl}_{2}\right)$}

The intermediate $\left[\mathrm{Ch}-\mathrm{OSO}_{3} \mathrm{H}\right] \mathrm{Cl}(\mathbf{1})$ was synthesized according to the reported methods, ${ }^{14}$ dried under vacuum to afford the white powder. The characterization data for the intermediate are as follows: $\left[\mathrm{Ch}-\mathrm{OSO}_{3} \mathrm{H}\right] \mathrm{Cl}$ (1): IR / cm ${ }^{-1}: 3417,3043,2987,1483,1405,1231,1038$, 985, 761, 628, $571 \mathrm{~cm}^{-1} .{ }^{1} \mathrm{H}$ NMR (300 MHz, $\left.\mathrm{D}_{2} \mathrm{O}\right): \delta$ 3.06 (s, 9H), 3.60-3.63 (t, 2H), 433-437 (m, 2H).

A mixture of the above intermediate $\left[\mathrm{Ch}-\mathrm{OSO}_{3} \mathrm{H}\right] \mathrm{Cl}$ (2.197 g; $10 \mathrm{mmol})$ and $\mathrm{ZnCl}_{2}(2.726 \mathrm{~g} ; 20 \mathrm{mmol})$ was rapidly grinded for $5 \mathrm{~min}$; then, the uniform mixture was heated for $2 \mathrm{~h}$ at $100^{\circ} \mathrm{C}$ to afford the target ionic liquid $\left[\mathrm{Ch}-\mathrm{OSO}_{3} \mathrm{H}\right] \mathrm{Cl} \cdot 2 \mathrm{ZnCl}_{2}$ (2). The characterization data for the compound are as follows: [Ch-OSO$\left.{ }_{3} \mathrm{H}\right] \mathrm{Cl} \cdot 2 \mathrm{ZnCl}_{2}$ (2): Analysis: Calculated (\%) for $\mathrm{C}_{5} \mathrm{H}_{14} \mathrm{Cl}_{5} \mathrm{NO}_{4} \mathrm{SZn}_{2}$ (486.767): C, 12.34; $\mathrm{H}$, 2.90; N, 2.88. Found (\%): C,12.05; H, 2.89; N, 2.83. IR / $\mathrm{cm}^{-1}: 3357,2975,2889,1650,1384,1089,881$, $662 \mathrm{~cm}^{-1} .{ }^{1} \mathrm{H}$ NMR $\left(300 \mathrm{MHz}, \mathrm{D}_{2} \mathrm{O}\right): \delta 3.13(\mathrm{~s}, 9 \mathrm{H})$, 3.65-3.67 (t, 2H), $440(\mathrm{~s}, 2 \mathrm{H}){ }^{13} \mathrm{C}$ NMR $(101 \mathrm{MHz}$, $\left.\mathrm{D}_{2} \mathrm{O}\right): \delta 51.05,59.12,61.91$. 2.3 General procedure for the Mannich-type reaction
catalyzed by $\left[\mathrm{Ch}-\mathrm{OSO}_{3} \mathrm{H}\right] \mathrm{Cl} \cdot 2 \mathrm{ZnCl}_{2}$

In a typical experiment (Scheme 1), to a roundbottomed flask charged with aromatic aldehyde $(10 \mathrm{mmol})$, aromatic amine $(10 \mathrm{mmol})$ and aromatic ketones (10 mmol) in 2-3 $\mathrm{mL} 85 \%$ aqueous ethanol was added $\left[\mathrm{Ch}-\mathrm{OSO}_{3} \mathrm{H}\right] \mathrm{Cl} \cdot 2 \mathrm{ZnCl}_{2}(0.49 \mathrm{~g} ; 1 \mathrm{mmol})$ under stirring. The mixture was then stirred for a length of time at room temperature. After completion of the condensation (monitored by TLC), the solid crude product was filtered and recrystallized from $95 \%$ ethanol to afford pure $\beta$-amino carbonyl derivatives. The products obtained were identified by ${ }^{1} \mathrm{H}$ NMR, and physical data (M.p.) with those reported in the literature. $\left[\mathrm{Ch}-\mathrm{OSO}_{3} \mathrm{H}\right] \mathrm{Cl} \cdot 2 \mathrm{ZnCl}_{2}$, could be recovered from the filtrate and reused directly for the next run without any treatment. The characterization data for the new compounds are given below.

2.3a 1-Phenyl-3-(p-hydroxylphenyl)-3-(m-trifluoromethylphenylamino)-1-propanone (Table 3, entry 13): White solid, M.p. $157-158^{\circ} \mathrm{C}$; Analysis: Calculated (\%) for $\mathrm{C}_{22} \mathrm{H}_{18} \mathrm{~F}_{3} \mathrm{NO}_{2}$ (385.379): $\mathrm{C}, 68.57 ; \mathrm{H}, 4.71$; $\mathrm{N}, 3.63$. Found (\%): C, 68.33; H,4.72; N, 3.58. MS $(\mathrm{m} / \mathrm{z}): 386.1308\left([\mathrm{M}+\mathrm{H}]^{+}\right) \cdot{ }^{1} \mathrm{H}$ NMR $(400 \mathrm{MHz}$, $\left.\mathrm{CDCl}_{3}\right) \quad \delta$ 7.94-7.86 (m, 2H), $7.58(\mathrm{t}, 1 \mathrm{H}), 7.46$ $(\mathrm{t}, 2 \mathrm{H}), 7.16(\mathrm{t}, 1 \mathrm{H}), 6.88(\mathrm{~d}, 1 \mathrm{H}), 6.79(\mathrm{dd}, 3 \mathrm{H}), 6.67$ (dd, 1H), 4.99-4.92 (m, 1H), $4.80(\mathrm{~s}, 2 \mathrm{H}), 3.60-3.22$ (m, 4H). ${ }^{13} \mathrm{C}$ NMR (101 MHz, $\left.\mathrm{CDCl}_{3}\right) \delta$ 197.26, $153.84,146.07,135.55,133.23,132.57,128.72$, $128.46,127.74,127.18,126.57,118.97,115.41$, $114.67,113.01,109.32,53.08,45.11$.

$2.3 \mathrm{~b} \quad 1-$ Phenyl-3-(p-methylphenyl)-3-(m-trifluoromethylphenylamino)-1-propanone (Table 3, entry 14): White solid, M.p. $111-112^{\circ} \mathrm{C}$; Analysis: Calculated (\%) for $\mathrm{C}_{23} \mathrm{H}_{20} \mathrm{~F}_{3} \mathrm{NO}$ (383.406): C, 72.05; H, 5.26; N, 3.65. Found (\%): C, 71.85; H, 5.28; N, 3.60. MS (m/z): $384.1520\left([\mathrm{M}+\mathrm{H}]^{+}\right) .{ }^{1} \mathrm{H}$ NMR $\left(400 \mathrm{MHz}, \mathrm{CDCl}_{3}\right) \delta$ 7.91 (dd, 2H), 7.60-7.50 (m, 2H), 7.45 (t, 2H), 7.31 (d, 2H), 7.16-7.12 (m, 3H), $6.89(\mathrm{~d}, 1 \mathrm{H}), 6.80(\mathrm{~s}, 1 \mathrm{H})$, $6.68(\mathrm{dd}, 1 \mathrm{H}), 4.98(\mathrm{dd}, 1 \mathrm{H}), 3.53-3.40$ (m, 2H), 2.31 $(\mathrm{s}, 3 \mathrm{H}) .{ }^{13} \mathrm{C} \mathrm{NMR}\left(101 \mathrm{MHz}, \mathrm{CDCl}_{3}\right) \delta 197.12,146.28$,

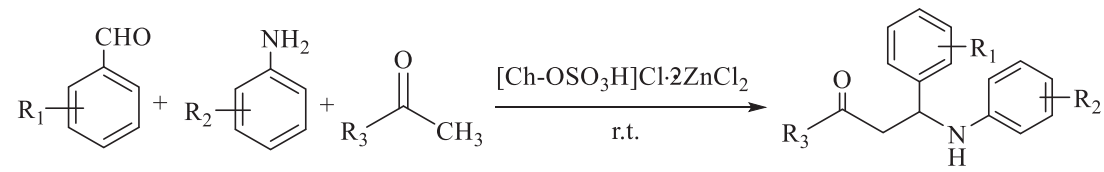

Scheme 1. Process of Mannich-type reaction. 
$137.99,136.24,135.54,132.53,130.43,128.60$, $128.49,127.72,127.18, \quad 125.12,120.08,115.34$, 113.10, 109.35, 53.36, 45.14, 20.04 .

\section{Results and Discussion}

\subsection{Synthesis and characterization}

The intermediate $\left[\mathrm{Ch}-\mathrm{OSO}_{3} \mathrm{H}\right] \mathrm{Cl}$ was synthesized according to the reported methods; then a mixture of $\left[\mathrm{Ch}-\mathrm{OSO}_{3} \mathrm{H}\right] \mathrm{Cl}$ and $\mathrm{ZnCl}_{2}$ was rapidly grinded for $5 \mathrm{~min}$, and heated for $2 \mathrm{~h}$ at $100^{\circ} \mathrm{C}$ to afford the target ionic liquid $\left[\mathrm{Ch}-\mathrm{OSO}_{3} \mathrm{H}\right] \mathrm{Cl} \cdot 2 \mathrm{ZnCl}_{2}$. In the FTIR spectrum for $\left[\mathrm{Ch}-\mathrm{OSO}_{3} \mathrm{H}\right] \mathrm{Cl} \cdot 2 \mathrm{ZnCl}_{2}$, (Figure $\mathrm{S} 2$ in Supplementary Information), the peaks of $\mathrm{O}-\mathrm{H}$ bond (3300-3500 $\left.\mathrm{cm}^{-1}\right), \mathrm{C}-\mathrm{H}$ bond $\left(2880-2990 \mathrm{~cm}^{-1}\right)$, C-O bond (1000-1100 $\mathrm{cm}^{-1}$ ) were well-retained. However, the $\mathrm{Zn}-\mathrm{Cl}$ vibration peak in $\mathrm{ZnCl}_{2}$ is at 503 $\mathrm{cm}^{-1}$, whereas the $\mathrm{Zn}-\mathrm{Cl}$ vibration peak in $\left[\mathrm{Ch}-\mathrm{OSO}_{3} \mathrm{H}\right]$ $\mathrm{Cl} \cdot 2 \mathrm{ZnCl}_{2}$ appears at $663 \mathrm{~cm}^{-1}$. The peak was enhanced and position shifted from $503 \mathrm{~cm}^{-1}$ to $663 \mathrm{~cm}^{-1}$, which indicated that the significant catalytic effect of [Ch$\left.\mathrm{OSO}_{3} \mathrm{H}\right] \mathrm{Cl} \cdot 2 \mathrm{ZnCl}_{2}$ is due to the complexation between $\left[\mathrm{Ch}-\mathrm{OSO}_{3} \mathrm{H}\right] \mathrm{Cl}$ and $\mathrm{ZnCl}_{2}$.

In order to understand the phase transition and decomposition behavior of $\left[\mathrm{Ch}-\mathrm{OSO}_{3} \mathrm{H}\right] \mathrm{Cl}$ and $[\mathrm{Ch}-$ $\left.\mathrm{OSO}_{3} \mathrm{H}\right] \mathrm{Cl} \cdot 2 \mathrm{ZnCl}_{2}$, DSC and TGA study were carried out. The results are shown in Figure 2. It can be seen that $\left[\mathrm{Ch}-\mathrm{OSO}_{3} \mathrm{H}\right] \mathrm{Cl}$ and $\left[\mathrm{Ch}-\mathrm{OSO}_{3} \mathrm{H}\right] \mathrm{Cl} \cdot 2 \mathrm{ZnCl}_{2}$ have high thermal stability. The addition of zinc chloride did not change significantly the thermal stability. The high thermal stability suggests that both of them can be used in a wide temperature range. In DSC for $\left[\mathrm{Ch}-\mathrm{OSO}_{3} \mathrm{H}\right] \mathrm{Cl}$, endothermic peaks appeared

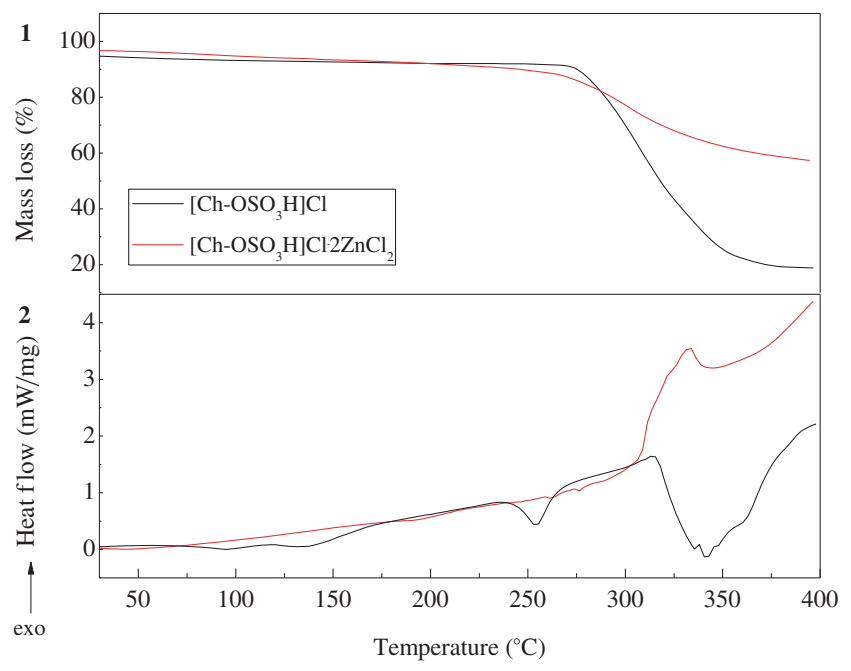

Figure 2. TGA (1) $-\mathrm{DSC}$ (2) scans of $\left[\mathrm{Ch}-\mathrm{OSO}_{3} \mathrm{H}\right] \mathrm{Cl}$ and $\left[\mathrm{Ch}-\mathrm{OSO}_{3} \mathrm{H}\right] \mathrm{Cl} \cdot 2 \mathrm{ZnCl}_{2}$. at $254.3^{\circ} \mathrm{C}$ and $341.6^{\circ} \mathrm{C}$. The peak at $254.3^{\circ} \mathrm{C}$ was due to the phase transition. $\left[\mathrm{Ch}-\mathrm{OSO}_{3} \mathrm{H}\right] \mathrm{Cl}$ had changed from solid into molten state. The melting enthalpy was $58.93 \mathrm{~J} / \mathrm{g}$. Another peak was due to the decomposition, the decomposing enthalpy was $509.5 \mathrm{~J} / \mathrm{g}$. The decomposing enthalpy of $\left[\mathrm{Ch}-\mathrm{OSO}_{3} \mathrm{H}\right] \mathrm{Cl} \cdot 2 \mathrm{ZnCl}_{2}$ was 509.5 $\mathrm{J} / \mathrm{g}$. The endothermic peak was at $344.6^{\circ} \mathrm{C}$.

One-pot Mannich-type model reaction with benzaldehyde, aniline and acetophenone was established in the presence of $\left[\mathrm{Ch}-\mathrm{OSO}_{3} \mathrm{H}\right] \mathrm{Cl} \cdot 2 \mathrm{ZnCl}_{2}$ and the reaction time was monitored by TLC (Table 1 ).

It showed that the three-component Mannich-type reaction could be accomplished smoothly in aqueous ethanol at room temperature. Satisfactory results were obtained in $80-85 \%$ ethanol medium (entries 5, 6). But, when pure water or ethanol were used as medium (entries 1, 7), the reaction was suppressed. The yield rose with the addition of ethanol in water, and the yield reached maximum when the content of ethanol is $85 \%$. It is noteworthy that the proposed catalyst $\left[\mathrm{Ch}-\mathrm{OSO}_{3} \mathrm{H}\right] \mathrm{Cl} \cdot 2 \mathrm{ZnCl}_{2}$ could retain its activity in the aqueous media. In aqueous media, most of the traditional Lewis acid catalysts may react with water first. It greatly affects the activity of catalyst, leading to lower yields of the target product. This work indicated that $\left[\mathrm{Ch}-\mathrm{OSO}_{3} \mathrm{H}\right] \mathrm{Cl} \cdot 2 \mathrm{ZnCl}_{2}$ overcame the fear of water when compared with many traditional Lewis acid catalysts. ${ }^{19-21}$

In order to evaluate the catalytic activity of [Ch$\left.\mathrm{OSO}_{3} \mathrm{H}\right] \mathrm{Cl} \cdot 2 \mathrm{ZnCl}_{2}$, different catalysts were explored in the model reaction (Table 2) in aqueous ethanol medium at the room temperature. It is inferred from Table 2 that $\left[\mathrm{Ch}-\mathrm{OSO}_{3} \mathrm{H}\right] \mathrm{Cl}$ catalyzed more effectively than choline chloride and results in substantial increase of yield (entries 1,2), which confirmed that the replacement of hydroxyl to sulfonic acid group could increase the catalytic activity. Besides, it could be inferred that $\mathrm{ZnCl}_{2}$ showed some catalytic activity and introducing

Table 1. The effects of different solvent systems to the Mannich reaction. ${ }^{\mathrm{a}}$

\begin{tabular}{lccc}
\hline Entry & Solvent & Time (min) & Yield $(\%)^{\mathrm{b}}$ \\
\hline 1 & $\mathrm{H}_{2} \mathrm{O}$ & 10 & $<10$ \\
2 & $50 \%$ ethanol & 8 & 59 \\
3 & $65 \%$ ethanol & 8 & 76 \\
4 & $75 \%$ ethanol & 8 & 86 \\
5 & $80 \%$ ethanol & 8 & 93 \\
6 & $85 \%$ ethanol & 8 & 98 \\
7 & $\mathrm{C}_{2} \mathrm{H}_{5} \mathrm{OH}$ & 8 & $<10$ \\
\hline
\end{tabular}

aReaction conditions: benzaldehyde (10 mmol), aniline (10 mmol) and acetophenone $(10 \mathrm{mmol})$, catalyst $(1 \mathrm{mmol})$,

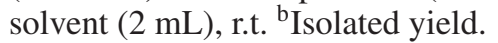


Table 2. The activity of different catalysts for Mannich reaction. ${ }^{\mathrm{a}}$

\begin{tabular}{lcc}
\hline Entry & Catalyst & Yield (\%) \\
\hline 1 & Choline Chloride & 51 \\
2 & {$\left[\mathrm{Ch}-\mathrm{OSO}_{3} \mathrm{H}\right] \mathrm{Cl}$} & 71 \\
3 & $\mathrm{ZnCl}_{2}$ & 55 \\
4 & $\mathrm{ChCl} \cdot 2 \mathrm{ZnCl}$ & 68 \\
$5^{\mathrm{b}}$ & $\mathrm{ChCl} \cdot 2 \mathrm{ZnCl}$ & 71 \\
6 & {$\left[\mathrm{Ch}-\mathrm{OSO}_{3} \mathrm{H}\right] \mathrm{Cl}$ and $\mathrm{ZnCl}_{2}$} & 61 \\
7 & {$\left[\mathrm{Ch}-\mathrm{OSO}_{3} \mathrm{H}\right] \mathrm{Cl} \cdot 2 \mathrm{ZnCl}$} & 98 \\
\hline
\end{tabular}

${ }^{a}$ Reaction conditions: benzaldehyde $(10 \mathrm{mmol})$, aniline $(10 \mathrm{mmol})$ and acetophenone $(10 \mathrm{mmol})$, catalyst $(1 \mathrm{mmol})$, $85 \%$ ethanol $(2 \mathrm{~mL}), 8$ h, r.t. ${ }^{b}$ In $\mathrm{H}_{2} \mathrm{O}$.

$\mathrm{ZnCl}_{2}$ would benefit the reaction (entry 3). However, the performance of individual use of the Lewis acid and Brønsted acid was unsatisfactory (entries 2, 3).

Based on the above results, we considered a combination of the Lewis acid and Brønsted acid. Initially, [Ch- $\left.\mathrm{OSO}_{3} \mathrm{H}\right] \mathrm{Cl}$ and $\mathrm{ZnCl}_{2}$ were mixed directly with a molar ratio of $1: 2$, and the mixture was simply used in the reaction without any pre-treatment (entry 6). But the catalytic effects were still unsatisfactory. However, if the pre-treatment process was optimized to grind them and heated under $100^{\circ} \mathrm{C}$ for $2 \mathrm{~h}$, the Lewis-Brønsted dual acid ionic liquid $\left(\left[\mathrm{Ch}-\mathrm{OSO}_{3} \mathrm{H}\right] \mathrm{Cl} \cdot 2 \mathrm{ZnCl}_{2}\right)$ was generated which showed significant catalytic effect on Mannich reaction (entry 7). Choline chloride and zinc chloride were treated in the same way, and used as the catalyst for Mannich reaction in $85 \%$ aqueous ethanol (entry 4), and in pure water (entry 5). It was found that the catalytic activity of $\mathrm{ChCl} \cdot 2 \mathrm{ZnCl}_{2}$ for Mannich reaction was far less than $\left[\mathrm{Ch}-\mathrm{OSO}_{3} \mathrm{H}\right] \mathrm{Cl} \cdot 2 \mathrm{ZnCl}_{2}$. Thus, it proved that a combination of Lewis and Brønsted acid under heated condition and sulfonic acid group played a significant role in promoting the catalytic activity of the catalyst.

Abott et al., pointed out that actual species presented in $\mathrm{ChCl} \cdot 2 \mathrm{ZnCl}_{2}$ which acted as Lewis acid catalyst, could be $\left[\mathrm{ZnCl}_{3}\right]^{-},\left[\mathrm{ZnCl}_{5}\right]^{-}$and $\left[\mathrm{ZnCl}_{7}\right]^{-} .{ }^{10} \mathrm{Liu}$ and coworkers reported $\left[\mathrm{HO}_{3} \mathrm{~S}-\left(\mathrm{CH}_{2}\right)_{4}-\mathrm{min}\right] \mathrm{Cl}-\mathrm{xZnCl} \mathrm{Zn}_{2}$ was Brønsted-Lewis acidic ionic liquid. Anion in the ionic liquid could be $\left[\mathrm{ZnCl}_{3}\right]^{-},\left[\mathrm{Zn}_{2} \mathrm{Cl}_{5}\right]^{-},\left[\mathrm{Zn}_{4} \mathrm{Cl}_{9}\right]^{-} .{ }^{22}$ The forms of anion existing in such structures are semiempirical. These species may attract a proton from acetophenone to give anionic enolate species. Moreover, $\left[\mathrm{Ch}-\mathrm{OSO}_{3} \mathrm{H}\right] \mathrm{Cl} \cdot 2 \mathrm{ZnCl}_{2}$ can form an acceptordonor complex with the aldehyde and the imine in the first stage. Therefore, addition of the enolate

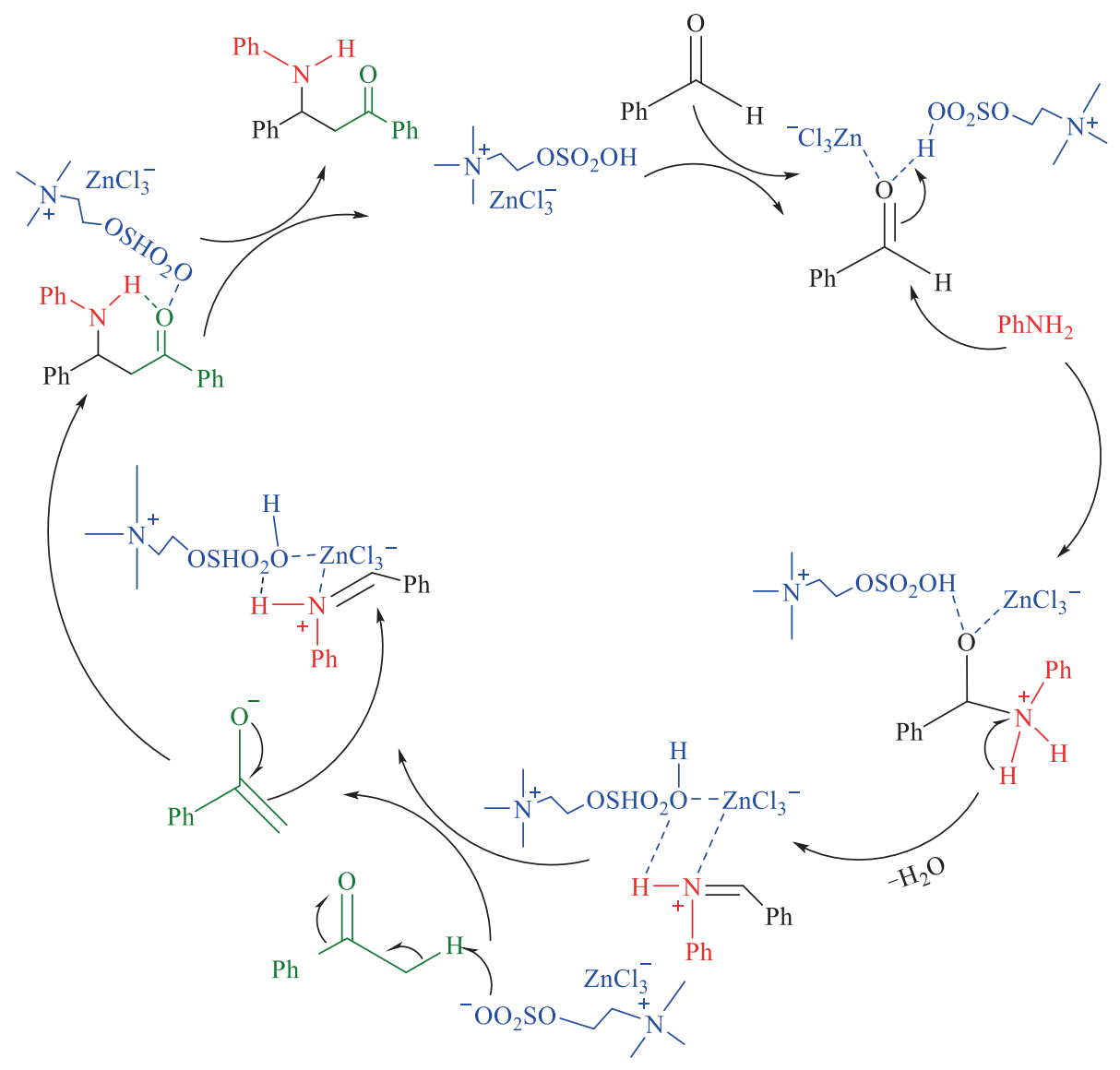

Scheme 2. The mechanism of $\left[\mathrm{Ch}-\mathrm{OSO}_{3} \mathrm{H}\right] \mathrm{Cl} \cdot 2 \mathrm{ZnCl}_{2}$-catalyzed Mannich-type reaction. 
form of acetophenone could be facilitated. When $\left[\mathrm{Ch}-\mathrm{OSO}_{3} \mathrm{H}\right] \mathrm{Cl}$ and $\mathrm{ZnCl}_{2}$ were mixed directly without any pre-treatment, they did not have such a catalytic effect.

On the basis of these assumptions, the experimental results and reported studies, the mechanism can be inferred. The mechanism of $\left[\mathrm{Ch}-\mathrm{OSO}_{3} \mathrm{H}\right] \mathrm{Cl} \cdot 2 \mathrm{ZnCl}_{2}$ catalysis of Mannich-type reaction involving benzaldehyde, aniline and acetophenone as substrate is shown in Scheme 2.

With the best reaction conditions in hand, some controlled experiments were explored with various aromatic aldehydes, aromatic amines and ketones as the substrate. The results presented in Table 3 shows that all the one-pot three-component Mannich-type reactions were accomplished in the optimal conditions, catalyzed by $\left[\mathrm{Ch}-\mathrm{OSO}_{3} \mathrm{H}\right] \mathrm{Cl} \cdot 2 \mathrm{ZnCl}_{2}$. It could be easily seen that no matter whether the electron donating group or the electron withdrawing group on the aromatic ring, reasonable to good yield could be obtained.

\subsection{Reusability of the catalyst}

In order to investigate the recycling of the catalyst, several repeat experiments were made with the recovered catalyst. The reaction was run with hydroxybenzaldehyde, p-toluidine and acetophenone as raw materials, $\left[\mathrm{Ch}-\mathrm{OSO}_{3} \mathrm{H}\right] \mathrm{Cl} \cdot 2 \mathrm{ZnCl}_{2}$ as the catalyst, $85 \%$ aqueous ethanol as the solvent. After the reaction, the mixture was filtered, washed several times with $85 \%$ aqueous ethanol. The filtrate containing the $\left[\mathrm{Ch}-\mathrm{OSO}_{3} \mathrm{H}\right] \mathrm{Cl} \cdot 2 \mathrm{ZnCl}_{2}$ was subsequently used as the catalyst - solvent system in the next run of the reaction.
The yield in the 5 cycles were 96, 96, 94, 93 and $92 \%$. In the $5^{\text {th }}$ cycle, the yield was slightly lower, which may be due to the unavoidable loss in the recovery process. But on the whole, the recovered catalyst still showed a significant catalytic activity on the reaction.

\subsection{The biodegradation rate of the catalyst $\left[\mathrm{Ch}-\mathrm{OSO}_{3} \mathrm{H}\right] \mathrm{Cl} \cdot 2 \mathrm{ZnCl} 2$}

Lastly, the biodegradation of $\left[\mathrm{Ch}-\mathrm{OSO}_{3} \mathrm{H}\right] \mathrm{Cl} \cdot 2 \mathrm{ZnCl}_{2}$ was investigated with the sludge of Nanjing sewage treatment plant. Sodium lauryl sulfate (SDS) was used as a reference. The standards were according to OECD301D. ${ }^{23}$ The results are shown in Figure 3.

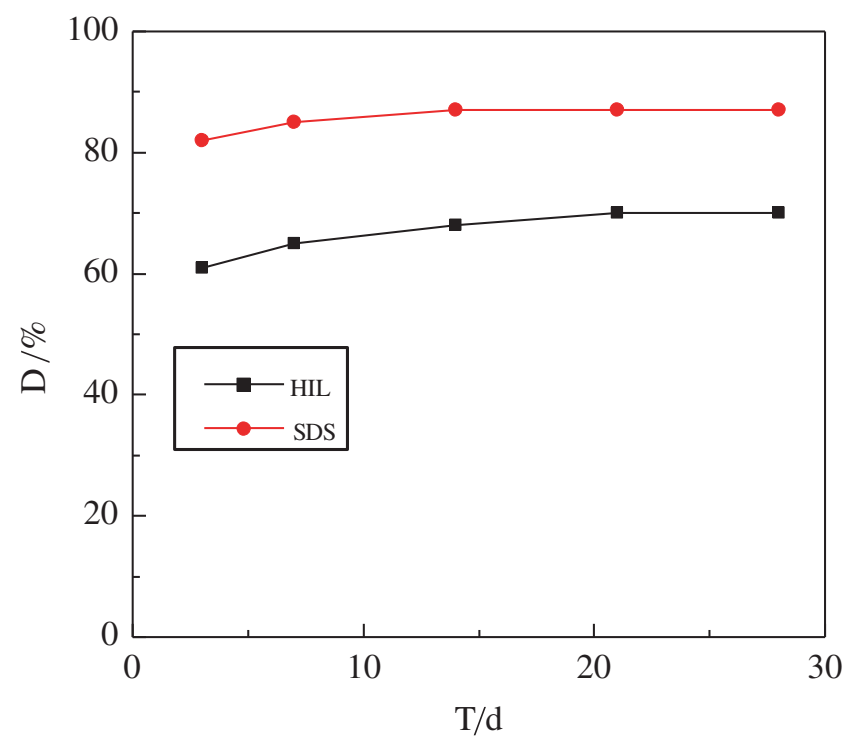

Figure 3. The biodegradation of the catalyst $\left[\mathrm{Ch}-\mathrm{OSO}_{3} \mathrm{H}\right] \mathrm{Cl} \cdot 2 \mathrm{ZnCl}_{2}$. Plot of $\mathrm{D}$ (\% vs time in days).

Table 3. $\left[\mathrm{Ch}-\mathrm{OSO}_{3} \mathrm{H}\right] \mathrm{Cl} \cdot 2 \mathrm{ZnCl}_{2}$-catalyzed three-component Mannich-type reaction. ${ }^{\text {a }}$

\begin{tabular}{lccccc}
\hline Entry & $\mathrm{R}_{1}$ & $\mathrm{R}_{2}$ & $\mathrm{R}_{3}$ & Yield $/ \%^{\mathrm{b}}$ & M.p. $\left({ }^{\circ} \mathrm{C}\right)$ \\
\hline 1 & $\mathrm{H}$ & $\mathrm{H}$ & $\mathrm{ph}$ & 98 & $153-154$ \\
2 & $\mathrm{H}$ & $4-\mathrm{Me}$ & $\mathrm{ph}$ & 86 & $163-164$ \\
3 & $4-\mathrm{Me}$ & $4-\mathrm{Me}$ & $\mathrm{ph}$ & 65 & $148-149$ \\
4 & $4-\mathrm{Me}$ & $4-\mathrm{Cl}$ & $\mathrm{ph}$ & 76 & $150-151$ \\
5 & $4-\mathrm{OCH}_{3}$ & $\mathrm{H}$ & $\mathrm{ph}$ & 93 & $106-107$ \\
6 & $4-\mathrm{OCH}$ & $4-\mathrm{Me}$ & $\mathrm{ph}$ & 84 & $157-158$ \\
7 & $4-\mathrm{F}$ & $4-\mathrm{Cl}$ & $\mathrm{ph}$ & 95 & $126-127$ \\
8 & $4-\mathrm{Cl}$ & $\mathrm{H}$ & $\mathrm{ph}$ & 87 & $117-118$ \\
9 & $4-\mathrm{Cl}$ & $4-\mathrm{Me}$ & $\mathrm{ph}$ & 91 & $152-153$ \\
10 & $4-\mathrm{Cl}$ & $4-\mathrm{Cl}$ & $\mathrm{ph}$ & 92 & $126-127$ \\
11 & $4-\mathrm{OH}$ & $\mathrm{H}$ & $\mathrm{ph}$ & 80 & $180-181$ \\
12 & $4-\mathrm{OH}$ & $4-\mathrm{Me}_{13}$ & $\mathrm{ph}$ & 96 & $171-172$ \\
13 & $4-\mathrm{OH}$ & $3-\mathrm{CF}_{3}$ & $\mathrm{ph}$ & 63 & $157-158$ \\
14 & $4-\mathrm{CH}$ & $3-\mathrm{CF}_{3}$ & $\mathrm{ph}$ & 73 & $111-112$ \\
15 & $\mathrm{H}$ & $\mathrm{H}$ & $4-\mathrm{MeC}_{6} \mathrm{H}_{4}$ & 86 & $138-139$ \\
\hline
\end{tabular}

a Reaction conditions: benzaldehyde $(10 \mathrm{mmol})$, aniline $(10 \mathrm{mmol})$ and acetophenone

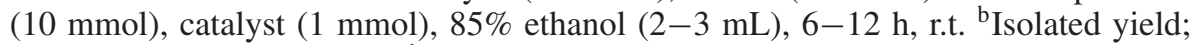
products were confirmed by ${ }^{1} \mathrm{H}$ NMR, MS. 
It was worth to note that the biodegradation rate of the catalyst can reach $70 \%$ after 3 weeks and remained stable subsequently. It was confirmed that $\left[\mathrm{Ch}-\mathrm{OSO}_{3} \mathrm{H}\right] \mathrm{Cl} \cdot 2 \mathrm{ZnCl}_{2}$ should be an easily biodegradable catalyst if compared with SDS, and this highlight was superior to our previous works.

\section{Conclusions}

In summary, a new biodegradable Lewis-Brønsted dual acid ionic liquid was discovered and used as the catalyst for the Mannich reaction of aromatic aldehydes, ketones and amines. The easily biodegradable catalyst could be recycled and reused. The procedure offers several advantages including high efficiency, good yield, and operational simplicity.

\section{Supplementary Information (SI)}

All additional information pertaining to characterization of the catalyst using elemental analysis (Table S1), IR spectra (Figures S1 and S3), ${ }^{1} \mathrm{H}$ NMR, ${ }^{13} \mathrm{C}$ MNR spectra (Figures S2, S4 and S5), and characterization of the new compounds using elemental analysis (Tables S2 and S3), MS (Figure S6 and S9), ${ }^{1} \mathrm{H}$ NMR, ${ }^{13} \mathrm{C}$ MNR spectra (Figures S7, S8, S10 and S11) are given in the supporting information, available at www.ias.ac.in/ chemsci.

\section{Acknowledgements}

We express our sincere thanks to the National Natural Science Foundation of China (21506115) and Natural Science Foundation of Jiangsu Province (CN) (BK20141257) for financial assistance.

\section{References}

1. (a) Veverkova E, Strasserova J, Sebesta R and Toma S 2010 Tetrahedron: Asymmetry 21 58; (b) Subramaniapillai S G 2013 J. Chem. Sci. 125467

2. (a) Roman G E 2015 J. Med. Chem. 89 743; (b) Gupta R P, Yadav B N and Srivastava A K 1985 Proc. Ind. Acad. Sci. (J. Chem. Sci.) 94475

3. (a) Nagarajan S and Kandasamy E 2014 Catal. Lett. 144 1507; (b) Sharghi H, Khalifeh R F, Beyzavi M M H, Beni A S and Doroodmand M M 2011 Iran. Chem. Soc. 8 S89; (c) Li G, Long R, Yang S and Zhang L 2011
Kinet. Catal. 52 559; (d) Ghatole A M, Lanjewar K R, Gaidhane M K and Hatzade K M 2015 Spectrochim. Acta, Part A $\mathbf{1 5 1} 515$

4. Yamashita Y, Matsumoto M, Chen Y J and Kobayashi S 2012 Tetrahedron $\mathbf{6 8} 7558$

5. Boomhoff M, Ukis R and Schneider C 2015 J. Org. Chem. 808236

6. Eshghi H, Rahimizadeh M, Hosseini M and Saraf A J 2013 Monatsh. Chem. 144197

7. Abo-Hamad A, Hayyan M, AlSaadi M A and Hashim M A 2015 Chem. Eng. J. 273551

8. Eshghi H, Rahimizadeh M, Saraf A J and Hosseini M 2015 Res. Chem. Intermed. 415049

9. Khandarkar K M, Shanti M D, Ahmed M and Meshram J S 2013 J. Chem. Sci. 1251573

10. (a) Abbott A P, Boothby D, Capper G, Davies D L and Rasheed R K 2004 J. Am. Chem. Soc. 126 9142; (b) Abbott A P, Nandhra S, Postlethwaite S, Simth E L and Ryder K S 2005 Phys. Chem. Chem. Phys. 9 3735; (c) Sunitha S, Kanjialal S, Reddy P S and Prasad R B N 2007 Tetrahedron Lett. 48 6962; (d) Zhu A L, Li L J, Wang J J and Zhuo K L 2011 Green. Chem. 13 1244; (f) Adeeb H, Mohd A H, Maan H, Farouq S M and Inas M A 2014 J. Cleaner Prod. 65246

11. (a) Liu F, Barrault J, Vigier K D O and Jérôme F 2012 Chem. Sus. Chem. 5 1223; (b) Chen X, Souvanhthong B, Wang H, Zheng H, Wang X and Huo M 2013 Appl. Catal. B 138-139 161

12. (a) Zhu A L, Liu R X, Li L J, Li L Y, Wang L and Wang J J 2009 Catal. Today 200 17; (b) Ilgen F, Ott D, Kralisch D, Reil C, Palmberger A and Konig B 2009 Green. Chem. 111948

13. Abbott A P, Capper G, Davies D L, Raymond K R and Tambyrajah V 2003 Chem. Commun. 170

14. (a) Satasia P S, Kalaria P N, Avalani J R and Raval D K 2014 Tetrahedron 70 5763; (b) Satasia S P, Kalaria P N and Raval D K 2014 J. Mol. Catal. A: Chem. 39141

15. Zhu A L, Li Q Q, Li L J and Wang J J 2013 Catal. Lett. 143463

16. Fariba K and Hossein T 2015 Catal. Lett. 1451062

17. Disale S T, Kale S R, Kahandal S S, Srinivasan T G and Jayaram R V 2012 Tetrahedron Lett. 532277

18. (a) Fang D, Luo J, Zhou X L and Liu Z L 2007 Catal. Lett. 116 76; (b) Fang D, Fei Z and Liu Z 2009 Catal. Commun. 10 1267; (c) Fang D, Jiang C N, Zhu T and Yang J M 2013 J. Chem. Sci. 125751

19. Kusum L C, Saravanan P, Rajesh K and Vinod K S 2002 Tetrahedron $\mathbf{5 8} 1369$

20. Rahmatpour A 2012 Polyhedron 4466

21. Kour M, Paul S, Clark J H, Gupta V K and Kant R 2016 J. Mol. Catal. A-Chem. 411299

22. Liu S W, Xie C X and Yu S T 2009 Chin. J. Catal. 30 401

23. Gathergood N, Garcia M T and Scammells P J 2004 Green. Chem. 6166 